\title{
Awareness of School Based Self-Evaluation for Quality Management
}

\author{
Sunshine Namasiku Siafwa ${ }^{1 *}$, Dr. Peter C. Manchishi ${ }^{2}$, Prof. Austin Mumba Cheyeka ${ }^{3}$ \\ School of Education, The University of Zambia, Zambia
}

*Corresponding Authors: Sunshine Namasiku Siafwa, School of Education, The University of Zambia, Zambia

\section{Abstract:}

Purpose: This paper discusses awareness by schools of school based self-evaluation (SBSE) in quality management in twenty selected public secondary schools in Lusaka Province, Zambia.

It attempts to establish awareness of SBSE in schools in order to assure quality management.

Methodology: The research design was a survey and a mixed methods approach was used. Data were collected using interviews and questionnaires. Interviews were thematically analysed and questionnaires were analysed using statistical package of social sciences. The population sample of three hundred and sixty (360) was used and this included administrators, teachers, pupils and support staff.

Findings: The findings of the study revealed that the participants had an idea what SBSE was, but they were not fully aware that a policy of SBSE from the Ministry of General Education existed. The findings further revealed that schools did not have a locally tailored policy, which made its application to attain assured quality management not effective.

Conclusion and Recommendations: The study concluded that there was no consistency in the way the participants became aware of SBSE. Lack of awareness has compromised the implementation of SBSE to attain quality management in most schools, as stakeholders did not fully appreciate their role in the process of SBSE. The study recommended that the schools were supposed have a deliberate policy, such as periodical refresher courses for administrators and on-going orientation of teachers on SBSE in order for the process to realise its objective.

Keywords: School Based Self-Evaluation, Management, Quality, Quality Management, Self-Evaluation

\section{INTRODUCTION}

The paper discusses the awareness of stakeholders in schools of school based self-evaluation in assuring quality management in twenty (20) selected public secondary schools in Lusaka Province, Zambia. The study was guided by Deming's Total Quality Management theory. According to Deming's Total Quality Management theory, the framework for transforming schools was based on his 14 TQM principles. Bonstingl (2001) outlined Deming's TQM principles he believed were most salient to education reform. He called them the "Four Pillars of Total Quality Management." These were synergies of relationships, continuous improvement and self-evaluation, system on-going process and leadership. According to Bonstingl (2001) in his first pillar, an organization was to focus, first and foremost, on its suppliers and customers. In a TQM organization, everyone was both a customer and supplier; this confusing concept emphasized "the systematic nature of the work in which all were involved". Kelchner (2008) concurred with Bonstingl (2001) by defining Total Quality Management as a system of continuous improvement that involved all workers in a business from upper management to production line workers. In other words, teamwork and collaboration were essential. Murray (2014) agreed to the definition by Kelchner (2008) by stating that 'TQM took into account all quality measures taken at all levels and involving all company employees. Based on the above pillars, SBSE can be achieved with the involvement of all stakeholders which includes administrators, teacher, pupils and support staff in a school. The study endeavoured to establish how aware the stakeholders were that SBSE was being implemented in their schools. 


\subsection{Background}

The system of evaluation in schools worldwide is going through changes in approach and one of the most innovative change, was moving from schools being evaluated by external evaluators to schools evaluating themselves. MacBeath (2003) stated that the need for schools to evaluate themselves was due to many reasons, in particular the high cost of external inspection systems and further stated that the direction of school and teacher evaluation in many education systems was undoubtedly moving towards internal school based self-evaluation. Grauwe and Naidoo (2004) suggested that selfevaluation was at the centre of almost all education quality improvement policies and strategies in most countries today.

Therefore, self-evaluation has the merit of being immediate, responsive to the school's specific needs and circumstances and its results are 'owned' by the school (OCED, 2009). When evaluation is conducted from within the school it is referred to as school based self-evaluation. According to MacBeath (2005a) self-evaluation is a process of reflection on practice, made systematic and transparent, with the aim of improving pupil, professional and learning outcomes.

Zambia has joined the rest of the world in introducing school based self-evaluation in schools. Furthermore, Zambia has been part of many world conferences that have discussed ways of improving the quality of education as part of the agenda. According to the policy document, 'Educating our Future' quality in education would be better assured if schools were dynamic in their pursuit of excellence (MOE, 1996: p.159). The document 'Educating our Future' is the national policy, therefore SBSE is a policy for public schools in Zambia.

In an effort to ensure that quality delivery of education took place, the Ministry of General Education revised the Standards and Evaluation guidelines of 1997 in 2015. In these guidelines highlights governing the implementation of self-evaluation by schools are given. The revision was important as it now called for all stakeholders to be involved in evaluating their contribution in their schools, which signified that the schools were now engaged in helping the system to achieve quality education.

\subsection{Review of Relate literature}

The concept of self-evaluation was diverse because it depended on the dimension one was looking at. In a school setting a number of evaluations can be done, some of which are teacher evaluation, student evaluation, school evaluation and system evaluation. In this study evaluation took the form of school based self-evaluation. Scheerens (2002) defined the term school based self-evaluation as 'the type of evaluation where the professionals in the programme or core service of the organisation carry out the evaluation in their own organisation. The process of carrying out the core service of the organisation involves stakeholders to ensure that success was achieved. To achieve this, it was important that the stakeholders were aware of the vision of the organisation. The study endeavoured to establish how aware the stakeholders in schools were of the SBSE.

The process of effective school based self-evaluation would bring about enhanced positive attitude/approach by all stakeholders, by so doing management would concentrate on more pertinent issues and would be able to make meaningful follow ups and this would bring about assured quality management. Frazier (1997) observed that if, as many people realized, that the cause of failures in education was a problem in design, and then quality management may be regarded as an ideal systemic process for managing change in public education.

According to Lunenburg, (2010) 'for schools, the purpose of the system must be clear and shared by all stakeholders - school board members, administrators, teachers, support staff, parents, community and students. Hence, awareness of the process of SBSE by stakeholder becomes very significant.

Checutti (2005) posited that 'a culture that promotes quality was painstakingly created by the schools: where the staff was fully committed and feels deeply responsible for the achievement of this vision; where a climate of collaboration and participation by all stakeholders permeates all initiatives, each and every one was determined to become an agent of change. Engaging staff members, volunteers, and other stakeholders in the design and implementation of an evaluation would provide opportunities for skill building and learning (NOAA, 2000). This could only be applied if the stakeholders were aware of SBSE.

All members of the school community needed to recognise their contribution to the schools' success and the actions required for further improvements (Ofsted, 2006). Effective school based self- 
evaluation provided the school with a mechanism to engage in open and transparent communication with the entire school community (DES, 2012). Awareness of SBSE by stakeholders would make the process effective as they would appreciate their role in the process.

One of the important features of school based self-evaluation/Inspection was the inclusion of administrators', teachers', students' and parents' perspectives in assessing school quality and developing improvement plans. In line with this, Chapman and Sammons (2013) stated that essentially, teachers and school leaders are the key agents of change. Ryan, Gandha, and Ahn, (2013) postulated that it would be critical to incorporate the views of a variety of key education stakeholders, including teachers as well as administrators. A school's unique features needed to shape its approach to improve planning and determine how it deployed its resources (Ofsted, 2006).

During SBSE it was important to ensure that evidence gathered was manageable, useful and focused. The process needed to involve staff at all levels, enabling them to recognise the contribution they could make to achieve the school's targets and how these related directly to teaching and learning. Starting points could be found in what teachers already knew about individual pupils (Ofsted, 2006). Gathering too much information could undermine each of these important considerations (DES, 2016). It was also important to ensure that the views of others formed part of the evidence base, therefore awareness of the process by all stakeholders was key.

\section{Methodology}

The design of the study was a survey and a mixed approach which was used concurrently. Quantitative and qualitative methods were used to collect data. Data were collected during the first and second term (February- July) -2016 school year.

A sample population of three hundred and sixty (360) participants selected from twenty public schools was used. In this study, non- probability sampling procedure was used, specifically purposive sampling to select the twenty (20) public secondary schools. Two schools from each of the seven districts in Lusaka were sampled and six (6) schools from Lusaka district due to the fact that it has a lot of schools. Total of three hundred sixty (360) participants which included eighty (80) administrators, four (4) per school; one hundred twenty (120) pupils, six (6) per school; one hundred twenty (120) teachers, six (6) per school and forty (40) support staff, two (2) per school were sampled. There were sixty one (61) male teachers and fifty nine (59) female teachers interviewed. The criteria for picking the sample population was that the teachers would have been in that particular school for a minimum of one year.

The researcher used semi-structured interview guides and questionnaires. The researcher gave out self-administered questionnaires to teachers which were collected after each participant completed answering. This ensured that all questionnaires were collected. After answering the questionnaires, the same participants were engaged in a focus group discussion which lasted for about 40-50minutes. With permission from the participants, the researcher recorded the discussions using an audio recorder to ensure accuracy of interview data. Face to face, in-depth interviews involving administrators were held. Qualitative method was used in order to develop in-depth understanding if the stakeholders in schools were aware of the implementation of SBSE to assure quality management, which was thematically analysed. For quantitative method the statistical package for social sciences (SPSS) was employed to translate findings into frequency tables and graphs to further collaborate the findings with the interviews that had been conducted.

\subsection{Scope of the Study}

This study focussed on establishing how aware the stakeholders in schools were of the implementation of school based self-evaluation in assuring quality management in twenty (20) selected public secondary schools in Lusaka Province, Zambia.

\section{FINDINGS AND DISCUSSION}

The objective of the study was to establish the awareness by stakeholders of school based selfevaluation in selected public secondary schools in Lusaka Province.

\subsection{Interviews with Administrators}

The findings revealed that most administrators that were interviewed had a fair understanding of what school based self-evaluation was all about, though most of them were more familiar with the term 
self-monitoring or assessment. They were able to define the term school based self-evaluation. One of the responses given was;

School based self-evaluation is the internal evaluation that is carried out by the school to monitor teachers as well as pupils in terms of academic performance'.

This response is in line with the definition given in the document produced by DES (2003), which defined school self-evaluation as a collaborative, inclusive, reflective process of internal school review. In the same view, MacBeath (2005a) added on that self-evaluation was a process of reflection on practice, made systematic and transparent, with the aim of improving pupil, professional and learning.

The implication of the knowledge of the definition of the phrase school based self-evaluation translated to mean that the administrators knew what was involved in the process of SBSE, therefore they would be able to tell if the process was on-going in their schools. Regarding what quality management was, the findings revealed that almost all administrators had a fair idea of what it was. One Deputy Headteacher had this to say;

Quality management is giving guidance to your subordinates in all areas. Like me as a deputy

Head I receive problems or requests from the Heads of Departments, I assess them and hand them to the Head. The Head gives guidance on which way to go.

In general SBSE was defined as efficient management of standards of resources, be it human, material and financial by school management. In line with this, Kelchner (2008) defined Total Quality Management as a system of continuous improvement that involved all workers in a business from upper management to production line workers. Goldberg and Cole (2002) stated that 'quality management provided a connection between outcomes and the process by which outcomes were achieved'.

The understanding of what quality management meant that the administrators had knowledge of what was expected of them in order to have quality management in their schools.

The fact that most administrators responded that they was a policy on SBSE by the Ministry of General Education was indicative that they understood what was required of them by the Ministry of General Education. What was apparently not clear was to what extent the stakeholders understood their part in it. Despite the administrators having the knowledge of the existence of the SBSE policy, answers on the specific policy on SBSE seemed to have been guess work, as answers differed significantly within the same school. From the answers given, it was indicative that these were the perceptions of the administrators on what they thought was SBSE. Despite the uncoordinated responses, the Ministry of General Education document on Standards and Evaluation guidelines (MESVTEE, 2015) gives guidance on SBSE to all schools in the Ministry of General Education. None of administrators seemed to have been aware of this. Each administrator named different sources of knowing about the SBSE policy, other than the standards and evaluation guidelines (2015). The implication was that despite most schools having a copy of the framework which included guidelines on self-evaluation, most administrators had not taken time to read and understand it. The document MESVTEE (2015) reads in part 'in order to understand the governance of learning institutions, Education Boards should ensure that the following policy documents are available and are followed by school management, teachers and other members of staff. It furthers reads that it was important that the documents be used to induct new teachers and other new members of staff in learning institutions or Education boards'. This did not seem to be the case in most schools sampled.

The standards and evaluation guideline names 52 documents (MESVTEE, 2015; 26) as a must read in all learning institutions and among them are policies pertaining to self-evaluation to ensure that quality was maintained. Some of the policy documents pertaining to self-evaluation included the monitoring and evaluation guidelines, planning for school Excellence Guidelines: Manual, Teaching Profession Act, vision 2030, tender and Procurement Act and Zambia Education Curriculum 2013. The impact of the administrators' failure to name any of the documents which were in the most schools showed lack of required awareness.

School self-evaluation would bring out the potential in leadership to redesign and improve the quality of support offered to schools, as well as recognition of the importance of equity and attention to using a broad set of evidence in policy making (OCED, 2013). This means that though the policy has been 
in existence but most administrators were not fully aware of it. Most administrators had the copy, but did not seem to have taken time to read through the copy.

The fact that there was no local policy on SBSE in all schools, confirmed the lack of complete awareness by most administrators of what was expected from them. This showed that the administrators did not follow guidelines from, MESVTEE (2015) which states that 'Education Boards/PTA/ACs/PCSs must ensure that there is a local policy on learner assessment, which prescribes the frequency of assessment. Head teachers were to ensure that this policy was implemented accordingly'. The study established that most schools did not have a local policy, which confirmed that awareness of what was expected of administrators in terms of the availability of a local policy was not there.

\subsection{Interviews with Teachers}

\subsubsection{Questionnaires with Teachers}

Figure1. Teachers defining Self Evaluation

\begin{tabular}{|l|l|l|}
\hline Definition & Frequency & Percentage \\
\hline Correct definition & 78 & 64 \\
\hline Partially correct definition & 42 & 36 \\
\hline Total teachers & $\mathbf{1 2 0}$ & $\mathbf{1 0 0}$ \\
\hline
\end{tabular}

Figure 1 showed that 42 teachers, which is 36 percent of the total defined School based selfevaluation well, while 78 which is 64 percent of the teachers defined it partially correct in line with the aforementioned set of definitions in the findings. The findings from the questionnaires revealed that most teachers also had a similar idea to the one the interviews with administrators yielded. What this brought was that more teachers were not well aware of what SBSE was, there were simply trying to make out what it could mean from the word.

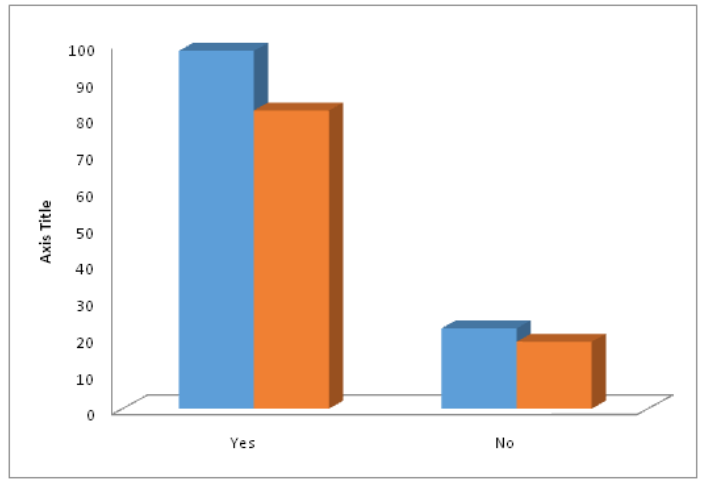

Figure2. Awareness of any policy on School Based Self-Evaluation

Figure 2 showed the responses from the questionnaires answered by teachers when asked if they were aware of any policy on school based self-evaluation by the Ministry of General Education, 81.7 percent of the participants responded in the affirmative while only 18.3 percent said they were not aware of any such policy. The findings did not agree with findings of the interviews which stated that most teachers were not aware of the policy by the Ministry of General Education on Self-evaluation. The negative responses during group discussions could have been influenced by group position. The questionnaires indicated the correct position as these were answered individually before the group discussion. The study deduced that awareness by teachers was assumed.

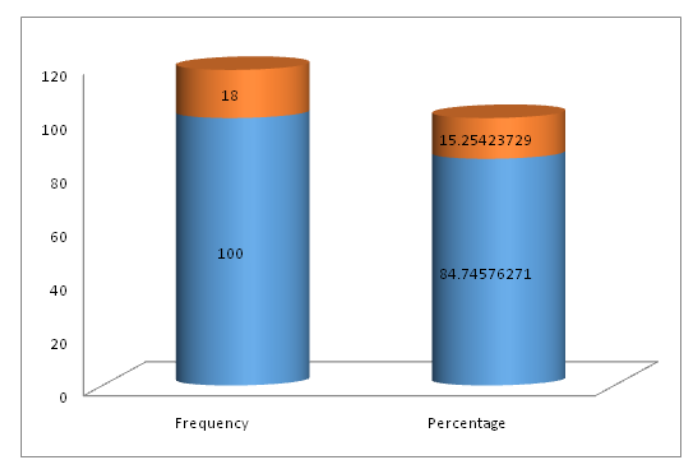

Figure3. Availability of a Policy on School based Self-Evaluation 
The teachers' responses (figure 3) from the questionnaires asking if their respective schools had a policy on school based self-evaluation. 84.7 percent of the teachers affirmed that there was a policy in their schools, while 15.3 percent negated this view. This in line with the responses of most administrators and teachers, which meant there were aware of a policy on SBSE. The study deducted that responses were not well representative of the actual awareness as what came out during discussions. This was confirmed by lack of a copy of the policy in the school. These findings make the awareness of SBSE questionable.

While most teachers displayed knowledge of what school based self-evaluation was, some of the responses indicated some kind of guesswork. Their responses that were in line with the correct definition can be summarised as 'school based self-evaluation is the internal evaluation that is carried out by the school to monitor teachers as well as pupils in terms of academic performance.' In support Chapman and Sammons (2013) stated that:

School self-evaluation is a process by which members of staff in a school reflect on their practice and identify areas for action to stimulate improvement in the areas of pupil and professional learning. These dimensions include: summative-formative; internally-externally driven; and whether self-evaluation is conducted as a top-down or bottom-up process.

The responses by the teachers confirmed that they were aware of what the word SBSE meant. On defining the word quality management, the teachers indicated that they had a fair understanding of the meaning of the word. One teacher described quality management as

where you make sure you follow what has been tabulated and when that happens the outcome will be good that is quality and if the outcome is bad that is not quality management'.

This description is in line with Goldberg and Cole (2002) who stated that quality management provided a connection between outcomes and the process by which outcomes are achieved. Similarly, Frazier (1997) observed that, if, as many people realized, the cause of failures in education was a problem in design, quality management may be regarded as an ideal systemic process for managing change in public education. Awareness of what quality management was, would ensure that there was conformity by teachers therefore, and reduce the chances of failure.

The lack of awareness by teachers of the local policy in SBSE in schools brings about the question of how implementation was being carried out. Most teachers were aware that there was some form of monitoring taking place in schools, and that the Continuous Professional Development practice which schools were doing was the policy being alluded to. The study revealed that most teachers were not aware of the SBSE policy from the Ministry of General Education, though most schools had copies in the Head teacher's office. This revealed lack of effective communication between the administrators and the teachers, lack of awareness meant there was ineffective implementation of SBSE.

The implication of lack of effective communication to the teachers is that they would not effectively apply themselves to achieve quality management. In line with effective communication DES (2012) states that effective school self-evaluation provided the school with a mechanism to engage in open and transparent communication with the entire school community

In line with this, the theory by Deming (2000) states that effective school based self-evaluation would foster communication that would be effective. In line with the theory, the document written by DES, (2012) state that effective school self-evaluation brought out school improvement when it involved principals, deputy principals, teachers and boards working together in a climate of trust and respect, in consultation with parents and pupils. For this to happen all stakeholders needed to be aware.

In similar view, Lunenburg (2010) observed that effective communication and the elimination of "demotivators", such as lack of involvement, poor information, the annual or merit rating, and supervisors who didn't care were critical. It meant removing achievement gaps for all population groups, a movement towards excellence and equity. Absence of proper communication and teamwork, meant effective school based self-evaluation could not be sustained. The study established that there was no effective communication in most schools, hence making SBSE awareness was feebly there. This implied that implementation of SBSE was weak due to haze awareness.

\subsection{Interviews with Pupils}

The findings were that most of the pupils understood what was meant by school based self-evaluation by the description that they gave. One pupil stated that; 
'To know how things are going on, where you are and the challenges you face, how the school is running and assessing yourselves'.

In line with this, Chapman and Sammons (2008) asserted that self-evaluation was appreciative selfinquiry in the USA. A 'self-review' was widely used, often synonymously with self-evaluation. In line with pupils answers Rolheiser and Ross (2000) defined self-evaluation as 'students judging the quality of their work, based on evidence and explicit criteria for the purpose of doing better work in the future' (p. 3).

The responses by the pupils were in line with those of administrators and teachers, a sign that there was some kind of awareness. Effective school self-evaluation provided the school with a mechanism to engage in open and transparent communication with the entire school community (DES, 2012). So communication in most schools was not inclusive, therefore awareness by most pupils was not conclusive.

Regarding what quality management was, one of the pupils described quality management as;

The way the school was being run by management involving everyone including the prefects to help them to keep discipline.

In line with this, Kelchner (2008) defined Total Quality Management as a system of continuous improvement that involved all workers in a business from upper management to production line workers. This indicated that the pupils understood quality management, the implication was that the pupils equally understood what was expected of their contributions in terms of standards

\subsection{Support staff}

The fact that most of the support staff interviewed were aware of what SBSE was and that they defined what quality management was, did not make them aware that it was a process on-going in their schools. Most administrators were not aware of what was happening in other departments other than in teaching and learning, as they had no other specialised training. In line with training, Kelchner (2008) stated that the employee training includes instruction in problem solving techniques and the tools to evaluate a process and identify weaknesses such as statistical process control. Training could help bring in awareness of expectations from all stakeholders.

The implication of participants not being aware that SBSE was taking place in their schools was that quality could not be assured. For effective SBSE to take place proper communication was needed. In line with this, Oliver and Conole (2000) stated that evaluation can fulfil a variety of roles in the quality assurance process, including acting as part of the quality assessment process or as a structure for devising quality enhancement plans.

\section{CONCLUSION AND RECOMMENDATIONS}

The study was to establish how aware the stakeholders in schools were of SBSE in assuring quality management. It can be noted that contrary to the participants' assumptions that they were aware of SBSE, the findings indicated that most of the stakeholders merely had an idea and they were not fully aware of on-going SBSE in their schools. The study concluded that there was no consistence in the way the participants came to know about SBSE, meaning the system of disseminating awareness was non-existent. The study further concluded that there was no form of deliberate policy of sensitizing stakeholders on the policy.

Furthermore, the study concluded that lack of awareness by some administrators was due to reading culture which was non-existent to most of the leaders in schools and therefore made it difficult for them implement policy instruction to their subordinates.

The findings of this study have implications for policy and practice. Therefore the study makes the following recommendations

- Ministry of General Education must ensure that there is mandatory training for all administrators before or immediately after taking office so that the administrators can acquaint themselves to all the policy documents that help them to run the schools.

- The study further recommends that deliberate policy for periodical mandatory refresher courses for the administrators to help them remain in touch with the guidelines by the MoGE. 
- Furthermore, the study recommends mandatory periodical orientation of teachers over the existing policy documents in order to ascertain conformity.

- The study further recommends that communication and collaboration in the schools must be strengthened so that all stakeholders become aware of SBSE and also what part they are expected to play in order to contribute effectively to assured quality management.

\section{REFERENCES}

[1] Bonstingl, J. J. (2008), Schools of Quality, Corwin Publishers, Ilinois.

[2] Chapman, C. and Sammons, P. (2008), Towards a framework for school-to-school networking in challenging circumstances', Educational research, 50 (4), 403-420.

[3] Chapman C. and Sammons, P. (2013), School self-evaluation for school improvement: what works and why? University of Oxford, London:

[4] Chetcuti, E. (2005), Schools' self-evaluation for improvement,

[5] De Grauwe, A. \& Naidoo, J. P. (2004), School Evaluation for quality improvement, UNESCO, Paris, available at: http://www.education.ie/en/The-Department/Management-Organisation/Inspectorate.html (accessed on 07 July, 2016).

[6] Department of Education and Science (2003), Looking at Our School: An aid to self-evaluation in primary schools. Available at: http://www.education.ie_(accessed on 30 June 2016).

[7] Department of Education and Science (2012), Guidance Teachers' standards, available at: https://www.gov.uk/government/publications/teachers-standards (accessed on 30 June 2016)

[8] Deming, W. E. (2000), Out of the crisis (rev. ed.). MIT Press, Cambridge, MA.

[9] Frazier, C. (1997), The Development of an Authentic Assessment Instrument: The scored discussion, TheEnglish Journal, 86(1), 37-40.

[10] Goldberg, J. S. and Cole, B. R. (2002), Quality Management in Education: Building Excellence and Equity in Student Performance, A\&M University, Texas.

[11] Kelchner, L. (2008), Theories of Total Quality Management, available at: http://smallbusiness.chro.com /theories -total-quality (accessed on 19 November 2016).

[12] Lunenburg, F. C. (2010). Total Quality Management Applied to Schools, Schooling. Sam Houston State University, vol 1, No. 1.

[13] MacBeath, J. (2003), The Self-Evaluation File, Learning Files Scotland, Glasgow.

[14] MacBeath, J. (2005), Self-evaluation: Models, tools and examples of practice. available at: http://www.ncsl. org.uk /media /93C/D5/self-evaluation-models-tools-and-examples-of practice pdf (accessed on 31 July 2016).

[15] Ministry of Education (1996), Educating our future - Policy paper of Zambian education, Ministry of Education, Lusaka.

[16] Ministry of Education Science, Vocational Training and Early Education (2015), Standards and Evaluation Guidelines, Directorate of Standards and Curriculum Department, Lusaka.

[17] Murray, A. (2014), Teacher Education Sourcebook 2014-15Teacher Education Services Murray State University, Kentucky.

[18] National Oceanic Atmospheric Administration (2000), Quality Management Program (HACCP QMP) Program Requirements, available at: https://www.st.nmfs.noaa.gov/data/Quality-Management/qualitymanagement (accessed on 03 July 2016).

[19] Organisation for Economic Cooperation and Development. (2009), Creating Effective Teaching and Learning Environments, OECD, Paris.

[20] Organisation for Economic Cooperation and Development. (2005), Teachers matter: Attracting, developing and retaining effective teachers, $\mathrm{OECD}$, Paris.

[21] Oliver, M. \& Conole, G. (2000), Assessing and enhancing quality using toolkits, Journal of Quality Assurance in Education, 8, 1, 32-37.

[22] Rolheiser, C., \& Ross, J. (2000), Student self-evaluation-What do we know? Orbit, 30(4), 33-36.

[23] Scheerens, J. (2002), School self-evaluation: Origins, Definition, Approaches, Methods and Implementation, in D. Nevo (Ed.), School-based evaluation: An international

[24] School-based evaluation in the Irish context, Educational Management Administration and Leadership, 34 (14), 564-582.

[25] The Inspectorate (2016), School Self-Evaluation Guidelines 2016-2020 Primary 2016, Department of Education and Skills, Dublin. 


\section{AUTHOR'S BIOGRAPHY}

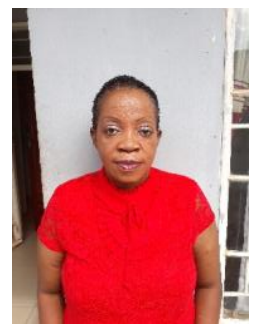

Sunshine Namasiku Siafwa holds a master's degree in Education and Development and is currently a Phd candidate at the University of Zambia. Her research interests are in Education administration, financial Management and Education Project Evaluation.

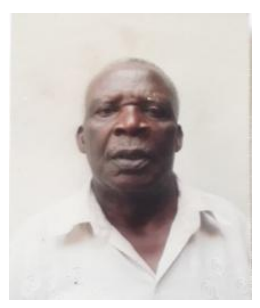

Peter C. Manchishi is a senior lecturer in the School of Education at the University of Zambia. He holds a Phd in Applied Linguistics. His research interests among others is in foreign Language Education.

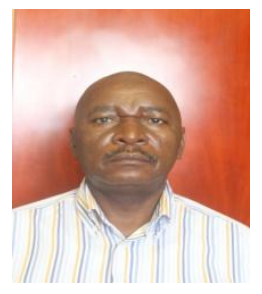

Austin Mumba Cheyeka is an Associate Professor in Religious Studies at the University of Zambia in the School of Education. Religion and Education is one of his specific research interests.

Citation: Sunshine Namasiku Siafwa, Dr. Peter C. Manchishi, Prof. Austin Mumba Cheyeka "Awareness of School Based Self-Evaluation for Quality Management" International Journal of Humanities Social Sciences and Education (IJHSSE), vol 5, no. 3, 2018, pp. 160-168. doi: http://dx.doi.org/10. 20 431/2349-0381.0503017.

Copyright: (1) 2018 Authors. This is an open-access article distributed under the terms of the Creative Commons Attribution License, which permits unrestricted use, distribution, and reproduction in any medium, provided the original author and source are credited. 